\title{
A Microstructure Obtained on AISI 1018 and AISI M2 Steel by Powder Paste Pack Boriding Process
}

\author{
G.J. Pérez Mendoza ${ }^{1}$, M. A. Doñu Ruiz ${ }^{1 *}$, N. López Perrusquia ${ }^{1}$, C. R. Torres San Miguel². \\ ${ }^{1 .}$ Grupo Ciencia e Ingeniería de Materiales, Universidad Politécnica del Valle de México, Tultitlan, \\ Estado de México. México \\ 2.Sección de Estudios de Posgrado e Investigación, Instituto Politécnico Nacional- ESIME Unidad \\ Zacatenco, Ciudad de México, México \\ * Corresponding author: marckdr_69@ hotmail.com
}

Surface treatment of boriding consists of the diffusing boron atoms on the surface of ferrous and nonferrous alloys, the result of treatment of a Fe base alloy is the formation of borides [1]. One of the advantages of borides is improved surface hardness, adhesive wear and high-temperature resistance [2]. In the present study, the double-layer microstructure has been investigated using a powder paste process on the surface of AISI 1018 and AISI M2 steel.

Samples of AISI 1018 and AISI M2 were used as a substrate, the samples are a cylindrical shape of nominal dimension of a diameter of $12.7 \mathrm{~mm}$ and $8 \mathrm{~mm}$ thickness, before the boriding, the samples were sanded with silicon carbide abrasive paper up to 600 grit and were cleaned with alcohol. The boronizing process was carried out with a commercial Durboride ${ }^{\odot}$ boron paste, the boron paste was dried at the temperature of $393 \mathrm{~K}$ for $20 \mathrm{~min}$ to remove water residues in the paste. The samples were embedded in a closed cylindrical case container (AISI 9840) at least $30 \mathrm{~mm}$ thick of boron dehydrate paste around each sample. Boriding was performed in a conventional electrical resistance furnace without an inert atmosphere at the temperature of $1273 \mathrm{~K}$ with $5 \mathrm{~h}$ of time exposure for each sample. At the end of the boriding process, the container was removed from the furnace and slowly cooled to room temperature. The samples were cross-sectional and resin-embedded for traditional metallographic preparation. The polish samples were etched with 2\% nital solution for AISI 1018 and vilella's reagent for AISI M2, to observed the boride layers depths formed on the surface on the substrate. Cross section of the samples was observed using scanning electron microscopy (SEM) with backscattered electron compositional (BEC) and the distribution of certain element on borided layers was determined by Energy Dispersive Spectroscopy (EDS) using JEOL JSM-6010LA. The X-ray Diffraction (XRD) analysis was conducted in a Bruker- $\mathrm{D} 8$ advance with $\mathrm{Cu} \mathrm{K} \alpha$ radiation and $2 \theta$ range of $20-100^{\circ}$.

SEM image of boron dehydrates paste with a particle size of $35 \pm 3 \mu \mathrm{m}$ before the boriding is shown in Figure 1a. The XRD pattern on boron dehydrate paste that identifies the presence of phases (majority $\mathrm{B}_{4} \mathrm{C}$ and activator $\mathrm{SiC}$ and $\mathrm{KBF}_{4}$ ) are displayed in Figure 1b. Cross-section SEM-BEC micrographs on the surface of AISI 1018 and AISI M2 steels are shown in Figure 2. The interface of the $\mathrm{FeB} / \mathrm{Fe}_{2} \mathrm{~B}$ and $\mathrm{Fe}_{2} \mathrm{~B} /$ substrate were observed saw-toothed morphology in AISI 1018 and flat morphology in AISI M2. Due to the potential of boron and alloying elements in substrates, there is an activated diffusion in the crystalline lattices of $\mathrm{Fe}_{2} \mathrm{~B}$ and $\mathrm{FeB}$ that reveal a sawn or flat morphology. In figure 3 is shown the EDS analysis obtained by SEM at the double layer $\left(\mathrm{FeB}+\mathrm{Fe}_{2} \mathrm{~B}\right.$ ) for AISI 1018 (Fig. 3a) and AISI M2 (Fig. $3 \mathrm{~b})$. The presence of $\mathrm{B}$ is observed, which allows the formation of iron borides $\mathrm{FeB}$ and $\mathrm{Fe}_{2} \mathrm{~B}$. In the case of AISI M2 steel the dissolution of $\mathrm{Cr}$ and Mo are observed, as well as the presence of carbides in the boride layer. Fig. 4a and Fig. 4b show the XRD patterns of AISI 1018 and AISI M2 steels boride, respectively. Both $\mathrm{FeB}$ and $\mathrm{Fe}_{2} \mathrm{~B}$ are identified by XRD in these two samples. In sample AISI M2, also 
identified is $\mathrm{CrB}$ phase. An alternative to obtaining a double boride layer $\left(\mathrm{FeB}+\mathrm{Fe}_{2} \mathrm{~B}\right)$ is through the process of powder paste in high alloy steel and low carbon that contributes to wear resistance.

Reference:

[1] Graf von Matuschka A. "Boronizing“", 1st ed. Carl Hanser Verlag, Munich, p. 12.

[2] I. E. Campos-Silva and G.A. Rodríguez-Castro, Thermochemical Surface Engineering of Steels, 1st ed., E.J. Mittemeijer and M.A.J. Somers, Ed., Woodhead-Elsevier Publishing, Cambridge, 2015, p. 651697.
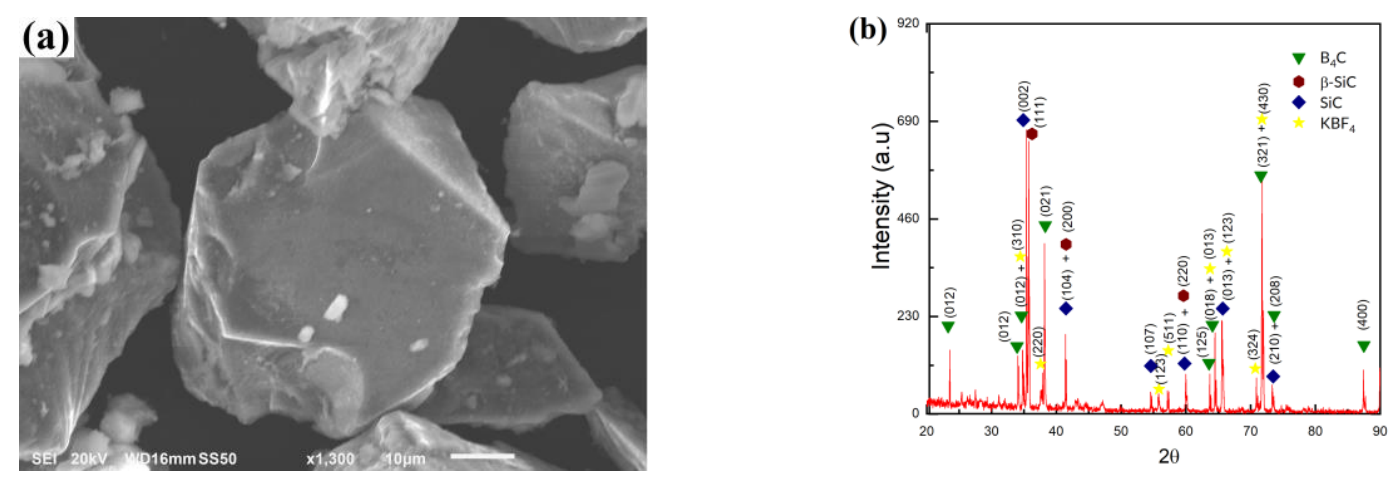

Figure 1. Durboride ${ }^{\odot}$ boron paste a) particle size and b) phase identification in the boron dehydrate paste used powder paste pack boride process.
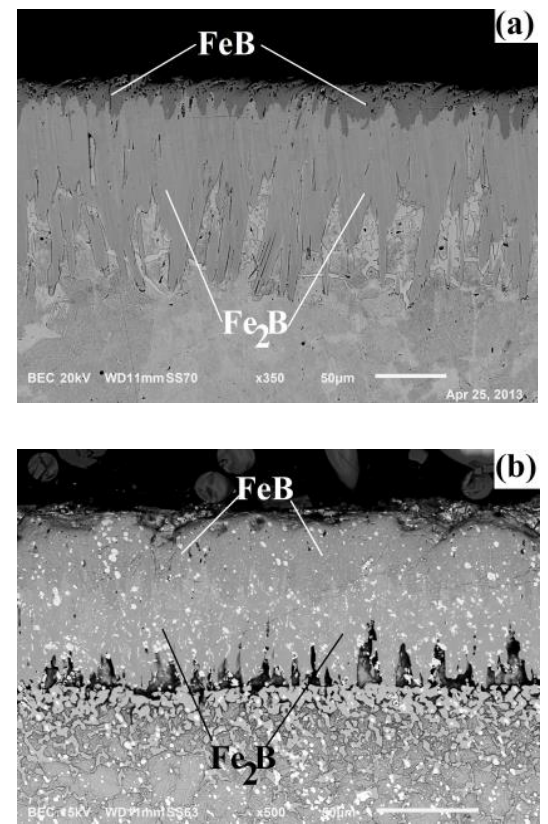

Figure 2. Cross-section micrograph of boride at 1273K a) AISI 1018 and b) AISI M2. (a)

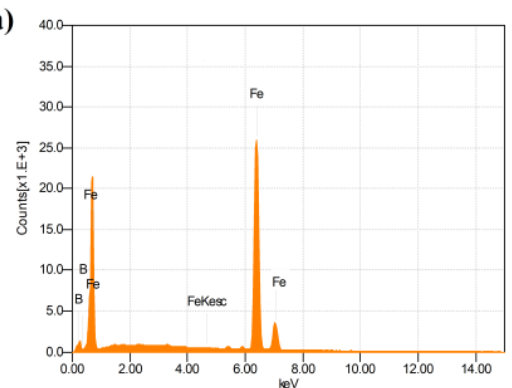

(b)

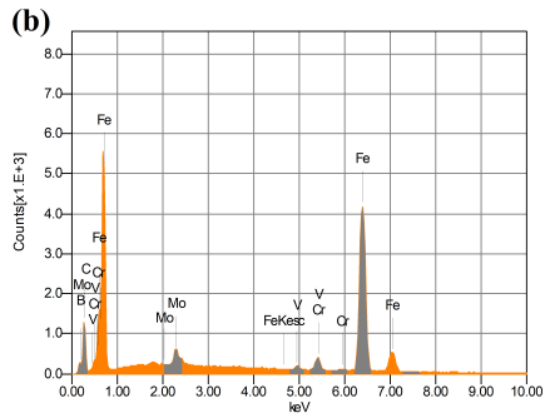

Figure 3. EDS results in: a) AISI 1018 and b) AISI M2.

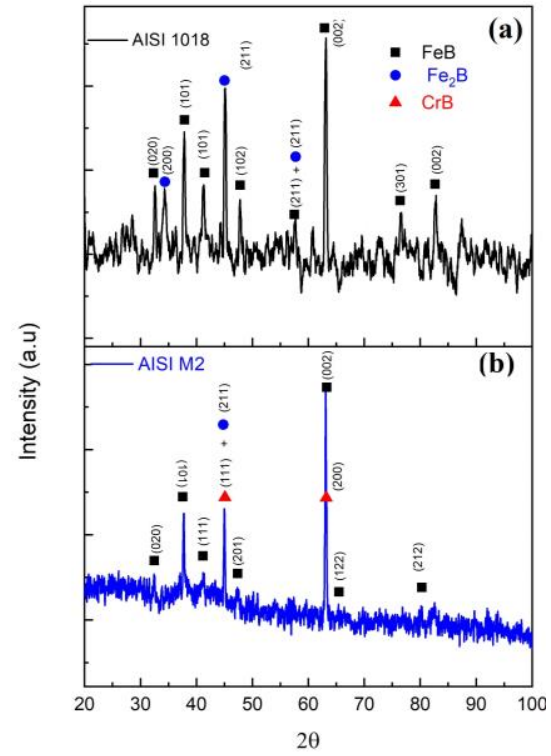

Figure 4. XRD pattern obtained in: a) AISI 1018 and b) AISI M2. 